University of South Carolina

Scholar Commons

$5-30-2014$

\title{
Probing the Roles of Polymeric Separators in Lithium-Ion Battery Capacity Fade at Elevated Temperatures
}

\author{
Jianchao Chen \\ University of South Carolina - Columbia, chenji@mailbox.sc.edu \\ Yongda Yan \\ Tao Sun \\ Yue Qi \\ Xiaodong Li \\ University of South Carolina - Columbia, lixiao@cec.sc.edu \\ Follow this and additional works at: https://scholarcommons.sc.edu/emec_facpub \\ Part of the Mechanical Engineering Commons
}

\author{
Publication Info \\ Published in Journal of The Electrochemical Society, Volume 161, Issue 9, 2014, pages A1241-A1246. \\ (C) Journal of The Electrochemical Society (2014), The Electrochemical Society (ECS). \\ (C) The Electrochemical Society, Inc. 2014. All rights reserved. Except as provided under U.S. copyright law, \\ this work may not be reproduced, resold, distributed, or modified without the express permission of The \\ Electrochemical Society (ECS). The archival version of this work was published in the Journal of The \\ Electrochemical Society. \\ Publisher's Version: http://dx.doi.org/10.1149/2.0351409jes \\ Chen, J., Yan, Y., Sun, T., Qi, Y., \& Li, X. (2014). Probing the Roles of Polymeric Separators in Lithium-lon \\ Battery Capacity Fade at Elevated Temperatures. Journal of The Electrochemical Society, 161 (9), \\ A1241-A1246. http://dx.doi.org/10.1149/2.0351409jes
}

This Article is brought to you by the Mechanical Engineering, Department of at Scholar Commons. It has been accepted for inclusion in Faculty Publications by an authorized administrator of Scholar Commons. For more information, please contact digres@mailbox.sc.edu. 


\title{
Probing the Roles of Polymeric Separators in Lithium-Ion Battery Capacity Fade at Elevated Temperatures
}

\author{
Jianchao Chen, ${ }^{\text {a,b }}$ Yongda Yan, ${ }^{a}$ Tao Sun, ${ }^{\mathrm{a}, \mathrm{z}}$ Yue Qi, ${ }^{\mathrm{c}, *, \mathrm{z}}$ and Xiaodong $\mathrm{Li}^{\mathrm{b}, \mathrm{d}, \mathrm{z}}$ \\ ${ }^{a}$ Center for Precision Engineering, Harbin Institute of Technology, Harbin 150001, People's Republic of China \\ ${ }^{b}$ Department of Mechanical Engineering, University of South Carolina, Columbia, South Carolina 29201, USA \\ ${ }^{c}$ Department of Chemical Engineering and Materials Science, Michigan State University, East Lansing, \\ Michigan 48824, USA \\ ${ }^{d}$ Department of Mechanical and Aerospace Engineering, University of Virginia, Charlottesville, Virginia 22904, USA
}

\begin{abstract}
The high temperature mechanical property of separators is very important for safety of lithium-ion batteries. However, the mechanical integrity of polymeric separators in lithium-ion batteries at elevated temperatures is still not well characterized. In this paper, the temperature dependent micro-scale morphology change of $\mathrm{PP}$ (polypropylene)-PE (polyethylene)-PP sandwiched separators (Celgard 2325) was studied by in-situ high temperature surface imaging using an atomic force microscope (AFM) coupled with power spectral density (PSD) analysis and digital image correlation (DIC) technique. Both PSD and DIC analysis results show that the PP phase significantly closes its pores by means of dilation of the nanofibrils surrounding the pores in the transverse direction and shrinkage in the machine direction, when cycled at $90^{\circ} \mathrm{C}$, even below the separator's shutdown temperature $\left(\sim 120^{\circ} \mathrm{C}\right)$ and its own melting temperature $\left(165^{\circ} \mathrm{C}\right)$. This is presumably due to surface melting effect in nanostructures and should be size dependent-the surface melting temperature may decrease with the diameter of nanofibrils. Therefore, some pore closing might happen even at operating temperatures, it will lead to capacity fade that is undesired for battery performance.
\end{abstract}

(C) 2014 The Electrochemical Society. [DOI: 10.1149/2.0351409jes] All rights reserved.

Manuscript submitted March 21, 2014; revised manuscript received May 1, 2014. Published May 30, 2014.

Secondary lithium ion batteries (Li-ion batteries) are increasingly employed in systems such as mobile electronics, space and aircraft power systems, plug-in hybrid electric vehicles (PHEVs), hybrid electric vehicles(HEVs), and all-electric vehicles (EVs), and smart grids because of their superior gravimetric and volumetric capacities. ${ }^{1,2}$ However, the development of Li-ion batteries for the mass market are also well-known to be plagued by its short shelf/cycle life (leading to higher costs), poor high temperature performance, and safety problems, which are essentially related to thermal effects in the battery. ${ }^{3}$ Therefore, insight into the Li-ion battery thermal effects attracts lots of attentions and will greatly promote the development of safe, reliable, and economical Li-ion battery systems for EVs, HEVs, and grid-scale energy storage.

In the studies of thermal effects in Li-ion batteries for transport applications, the temperature range can be categorized into operation range $\left(-30^{\circ} \mathrm{C}\right.$ to $\left.52^{\circ} \mathrm{C}\right)$, survival range $\left(-46^{\circ} \mathrm{C}\right.$ to $\left.66^{\circ} \mathrm{C}\right)$, and high temperature range, ${ }^{4}$ while the requirement for separator changes with temperature. Capacity fade is usually reported when storing and/or cycling batteries at temperatures up to $50^{\circ} \mathrm{C}$ or $70^{\circ} \mathrm{C}$ regardless of discharge rate. ${ }^{5-11}$ For instance, Ehrlich ${ }^{12}$ tested Sanyo $\mathrm{C} / \mathrm{LiCoO}_{2}$ full cells stored at temperatures ranging from 0 to $60^{\circ} \mathrm{C}$ and revealed that only $20 \%$ of the capacity is retained after 6 months for a $60^{\circ} \mathrm{C}$ storage temperature. Amine et al. ${ }^{6}$ studied prismatic cells composed of graphite (mesocarbon microbeads) for the negative and $\mathrm{LiFePO}_{4}$ material with an olivine-type structure for the positive electrode and observed that $70 \%$ of the initial capacity is lost after 100 cycles at $55^{\circ} \mathrm{C}$ whereas the cell cycles extremely well with no capacity fade up to 100 cycles at room temperature. It is commonly believed that this capacity degradation are ascribed to cell chemistry coupled with temperature - the degradation of active electrode material,${ }^{6}$ the solid electrolyte interphase (SEI) evolution, ${ }^{13,14}$ and the reaction of electrode material/binder/electrolyte. ${ }^{3,10}$ In this temperature range, the separator physically separates the anode and cathode electrodes to prevent internal short circuiting while permitting free flow of lithium ions in the liquid electrolyte throughout their interconnected porous structure. Any closure of pores will directly impede the movement of ions in electrolyte, resulting in battery performance degradation. ${ }^{15}$ At higher temperature, it is required that the separator shuts down the battery operation by closing its pores to prevent thermal runaway and thus enhance the safety of Li-ion batteries.

*Electrochemical Society Active Member.

žE-mail: taosun@hit.edu.cn; yueqi@egr.msu.edu; xl3p@ virginia.edu
According to the material composition, commercial separators can be broadly classified into three types: porous polymeric membranes, nonwoven mats, and inorganic composite membranes. ${ }^{16} \mathrm{Ow}-$ ing to their overwhelming advantages such as small thickness (critical for high power capability and high volumetric capacities), good mechanical strength, excellent electrochemical resistance, and shutdown capability (closing the pores to shut the battery down when overheating occurs), the porous polymeric membranes (polymeric separators) are dominating the Li-ion battery separator market. ${ }^{15}$ They are made of polyolefin materials such as polyethylene (PE, having a melting point of $120-130^{\circ} \mathrm{C}$ and a shutdown temperature that is slightly lower than melting point) and polypropylene (PP, melting point of $165^{\circ} \mathrm{C}$, shutdown point of $\sim 160^{\circ} \mathrm{C}$ ) through either a dry process or wet process. ${ }^{15,16}$ Besides the PE/PP monolayer separators, membranes made by laminating layers of PP and PE, e.g. PP-PE bilayer and PPPE-PP trilayer, are also available with added thermal abuse tolerance since PE layer can melt to close the pores when overheating occurs while PP layer provides mechanically dimensional support to prevent an internal short circuit between the electrodes. Furthermore, exactly because of this potential hazard of internal short circuiting most separator research mainly focuses on developing and fabricating higher temperature stable $\left(>\sim 130^{\circ} \mathrm{C}\right)$ alternatives by using new materials ${ }^{17-20}$ or by coating on the conventional PE/PP separators with thermal-stable ceramic particles. ${ }^{21,22}$

Although the morphological and mechanical properties requirement for separators change with temperature, there is little study in the literature on the morphology evolution and/or mechanical behavior of the widely used commercial polymeric separators in the temperature range between operating temperature and melt-down temperature, for example $90^{\circ} \mathrm{C}$ and its consequence on the battery performance. Norin et al. ${ }^{23,24}$ have examined the separator membranes (Celgard 2300, PP-PE-PP trilayer structure) that were taken from cells either shallowly ( $\pm 1.5 \%$ SOC) cycled at $45^{\circ} \mathrm{C}$ or stored at $55^{\circ} \mathrm{C}$ for up to 28 weeks. They found that the temperature at which the cell was stored/cycled had a significant impact on the cell capacity loss and membrane impedance rise: the cells lost $10 \%$ and $24 \%$ of their initial capacity for cycled and stored condition, respectively, and the separators' impedance increases $6 \%$ and $25 \%$ for membranes in cycled and stored cells, respectively. The causes for the membrane impedance increase were found to be a significant loss in porosity that was revealed by atomic force microscopy. ${ }^{23}$ They ascribed this porosity loss to the thermal decomposition of the electrolyte $\left(\mathrm{LiPF}_{6}-\mathrm{EC}-\mathrm{EMC}\right.$ electrolyte, the most widely used commercial electrolyte), the product of which precipitates on the separator and clogs the pores in the 
separator surface. ${ }^{24}$ Although Norin et al.'s studies well established that the porosity loss leads to an increase of the separator impedance, which accounts for $10 \%$ of the cell impedance rise, directly resulting in capacity loss, the behavior of separator itself when stored/cycled at elevated temperature is still unknown.

To decouple the impact of the side reactions of electrolyte from pore closing and to study solely on the separator itself are thus critically needed to elucidate the role of separator in the battery performance and safety at elevated temperatures $\left(<90^{\circ} \mathrm{C}\right)$ and to promote the understanding of batteries durability and robustness. Therefore, in this study, we have employed atomic force microscope (AFM) combined with a hot stage to image the surfaces of a widely used commercial polymeric porous separator at elevated temperatures. Comparing to another imaging technique-the scanning electron microscope (SEM) that is commonly used by separator researchers, the AFM hardly damages the separator surfaces, because non-conducting separators have to be sputter-coated with a thin layer of gold/carbon prior to SEM characterization to achieve high resolution at high operation voltages. With the aim of investigating the morphology evolution, especially the changes of pores of separator, we have analyzed the AFM images by means of the power spectral density (PSD), which provides a representation of the amplitude of a surface morphology as a function of the spatial frequency of the morphology and enables the revealing of the separator pore structures that might otherwise appear "random". ${ }^{25}$ Furthermore, a more macro view of the separator morphology evolution was achieved by accompanying the PSD analysis with digital image correlation (DIC) analysis, which has been widely used to measure local micro-scale deformation. ${ }^{26-28}$ We found that separator when cycled at $90^{\circ} \mathrm{C}$ can significantly close its pores in the transverse direction (TD) and shrink in the machine direction (MD), which will thus increase the cell internal impedance that is harmful for cell capacity retention.

\section{Experimental}

Separator investigated.- A commercially available polymeric separator, Celgard 2325, was investigated in this work. Celgard 2325 is 3-layered laminate with a polyethylene (PE) core between two polypropylene (PP) skin layers. The slit-like nano-pores are introduced through a dry process, in which the membrane is subjected to a uniaxial stretching. This process leads to a non-isotropic microstructure, giving the membrane two distinct material directions which are commonly referred to the machine direction (MD) and transverse direction (TD).

Temperature-controlled AFM imaging.- An AFM (Dimension Icon, Bruker corp.) equipped with a hot stage (TAC, Bruker corp.) employing resistive heating as a source of heat was used to image the separator surface (the PP phase for the separator studied here) at elevated temperatures, as shown in Fig. 1a and 1c. The ceramic probe holder is specially designed to thermally insulate the heater from the thermally sensitive piezoelectric devices and to actively heat the probe (uncoated etched silicon probe, BudgetSensors TAP300-G, Innovative Solutions Bulgaria Ltd.) to avoid condensation of moisture on the cantilever. The AFM was operated under tapping mode to obtain height and phase images simultaneously. The samples, in the form of $10 \mathrm{~mm}$ long strips with a width of $8 \mathrm{~mm}$, were cut using a razor blade. Each sample was glued at its two ends in the MD on a steel sample puck (12 $\mathrm{mm}$ in diameter) with superglue. Before placing the puck onto the heater stage, a small amount of thermal compound under the sample puck was spread to improve the temperature homogeneity and to minimize the temperature gradient between heater and sample surface. To achieve the calibration of sample temperature as a function of hot stage nominal temperature, a thermal couple (PT-1, Jiamin Co.) was used to measure the sample surface temperature independently. Base on the calibration data, a given sample surface temperature can be readily and precisely obtained.

In this work, we designed two experimental setups: (1) "stored condition": every separator surface image was taken at room temper- (a)
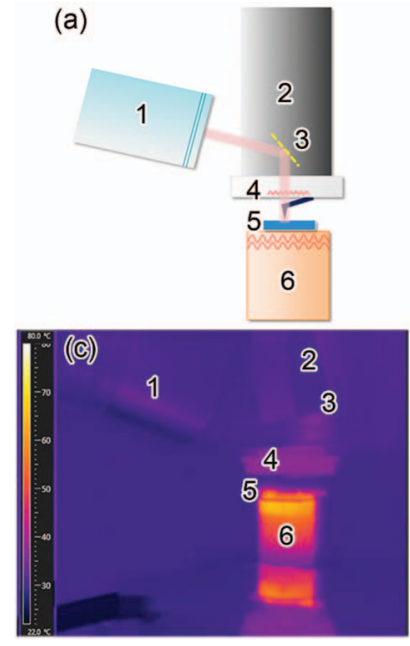

(b) In-situ imaging at RT

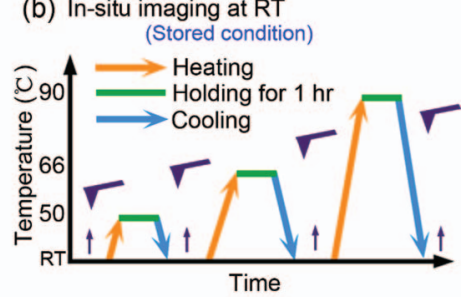

(d) In-situ imaging at holding stage (Cycled condition)

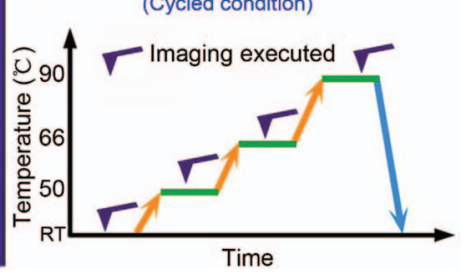

Figure 1. (a) Schematic illustration and (c) infrared image of AFM and heater configuration. The infrared image was captured by an infrared camera (FLIR A325sc, FLIR Systems, Inc.). 1: optical microscope with CCD, 2: piezoscanner, 3: reflective mirror, 4: ceramic probe holder, 5: sample, 6: heater with embedded heater filament. In-situ AFM imaging procedures: (b) "stored condition": imaging once the sample surface cooled down to room temperature (RT) to simulate the scenario that battery was operated at RT after being stored at elevated temperatures; (d) "cycled condition": in-situ imaging sample surfaces at temperature holding stage-imaging at $\mathrm{RT}, 50^{\circ} \mathrm{C}, 66^{\circ} \mathrm{C}$, and $90^{\circ} \mathrm{C}$ to mimic the condition that batteries are cycled at elevated temperatures.

ature (RT): as shown in Fig. 1b, the sample was heated up to a certain temperature, such as $50^{\circ} \mathrm{C}, 66^{\circ} \mathrm{C}$, and $90^{\circ} \mathrm{C}$, and then was cooled down to RT after 1 hour temperature holding; (2) "cycled condition": in-situ imaging separator surfaces at RT, then heating the sample to $50^{\circ} \mathrm{C}$ and holding the temperature for 1 hour which was then followed by imaging the same area. After imaging, the sample was then heated up to $66^{\circ} \mathrm{C}$ and the AFM started to image after holding the temperature for 1 hour, and as so on for $90^{\circ} \mathrm{C}$ scenario, which is illustrated in Fig. 1d. The former setups was used to mimic the scenario that battery was operated at RT after being stored at elevated temperatures while the latter was used to simulate the condition that battery was cycled at elevated temperatures. The specific value of temperatures $\left(50^{\circ} \mathrm{C}\right.$ and $66^{\circ} \mathrm{C}$ ) were determined by taking the upper limit of operation temperature range $\left(-30^{\circ} \mathrm{C}\right.$ to $\left.52^{\circ} \mathrm{C}\right)$ and survival temperature range $\left(-46^{\circ} \mathrm{C}\right.$ to $\left.66^{\circ} \mathrm{C}\right)$ which recommended by the U.S. Department of Energy USDOE FreedomCAR and Vehicle Technologies Program. ${ }^{4}$ And the $90^{\circ} \mathrm{C}$ was also examined as the intermediate temperature between operating $\left(52^{\circ} \mathrm{C}\right)$ and melting down $\left(120^{\circ} \mathrm{C}\right)$.

Digital image correlation (DIC).- The optical microscope integrated in the AFM was used to capture the optical images of sample prior to surface imaging/scanning by AFM. The optical images obtained at each step were processed using a Vic-2D 2009 DIC program package (Correlated Solutions Inc.). Two-dimensional surface displacement and strain field maps were constructed by comparing the optical images of the same area of each sample before and after heat-treatment. For details about DIC, please see Refs 27 and 29.

\section{PSD Calculation}

All AFM images of surfaces obtained in this study are in the form of discreet digitized data of surface heights as a two dimensional (2D) square array in the form of $z_{m, n}$ with pixel dimensions $\Delta x$ and $\Delta y$ $(\Delta x=\Delta y), M$ and $N$ pixels $(M=N)$ in the $x$ (TD) and $y(\mathrm{MD})$ directions, respectively. The 2D PSD distribution can be evaluated 

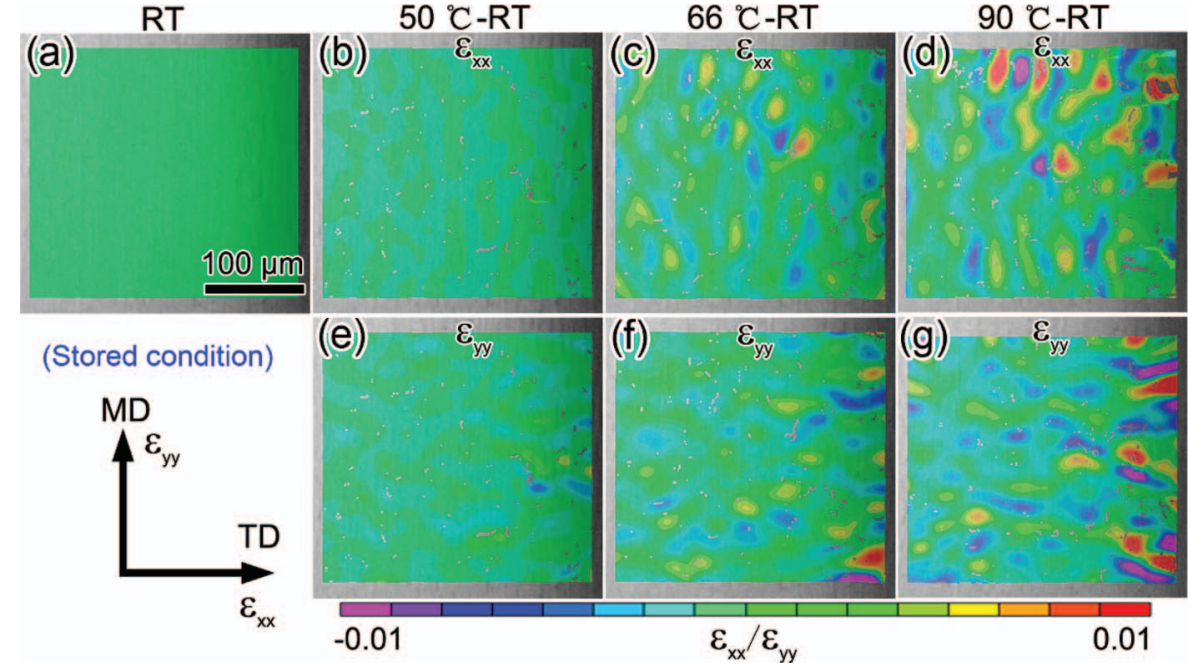

\section{$90{ }^{\circ} \mathrm{C}-\mathrm{RT}$}

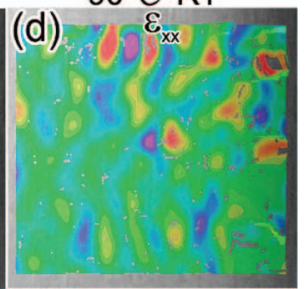

Figure 2. (a) Optical micrograph of separator surface before heating (as-received). DIC strain maps in the (b-d) transverse direction and in the (e-g) machine direction of the rectangle area in (a) after heat treatments at different temperatures (optical images were taken at RT): (b) and (e) $50^{\circ} \mathrm{C}$; (c) and (f) $66^{\circ} \mathrm{C}$; (d) and (g) $90^{\circ} \mathrm{C}$. Arrows under (a) indicate the orientation of the positive color-coded horizontal strain $\varepsilon_{\mathrm{xx}} / \varepsilon_{\mathrm{yy}}$. from the height distribution $z_{m, n}$ via equation

$$
\begin{aligned}
& P S D_{2 D}\left(f_{l}, f_{k}\right) \\
& =\frac{\Delta x \Delta y}{M N}\left|\sum_{m=0}^{M-1} \sum_{n=0}^{N-1} z_{m, n} \exp [-2 \pi i(m l / M+n k / N)]\right|^{2}
\end{aligned}
$$

Where $0 \leq l \leq M-1,0 \leq k \leq N-1$ and $f_{l}=l /(N \Delta x)=l / L, f_{k}=k /(N \Delta y)$ $=k / L$, where $L$ is the maximum dimension of scan size. The unit of the 2D PSD is length to the fourth power.

The 2D PSD can be integrated along a direction to obtain one dimension PSD (1D PSD): the discreet integrated 1D PSD in the $x$ direction (TD) - 1D PSD $\left(f_{l}\right)$ is obtained by integrating the 2D PSD over $f_{k}$ (vice versa, for $1 \mathrm{D}$ PSD in the MD- $\operatorname{PSD}\left(f_{k}\right)$ obtained by integrating over $f_{l}$ ) 1D PSD as

$$
P S D_{1 D}\left(f_{l}\right)=\sum_{l=0}^{M-1} P S D_{2 D}\left(f_{l}, f_{k}\right) \Delta f_{k}
$$

The unit of the 1D PSD is length to the third power. The frequency range of a $1 D$ PSD starts at the lower end with $1 / L$ and goes up to $N / 2$ times of this frequency, $1 /(2 \Delta x)$.

\section{Results and Discussion}

Strain filed mapping of the separators at elevated temperatures with DIC. - To investigate the thermal-induced morphology evolution of separator at the macro scale, we performed in-situ optical imaging on the separator surfaces with an optical microscope integrated in the AFM. The sample was rapidly heated up to the designated temperatures and hold for at least 1 hour before imaging. Then the optical images were taken at high temperatures and RT, as explained in Fig. 1b and $1 \mathrm{~d}$. The optical images of the as-received un-heated separators were used as the reference images for processing the images obtained from the heat-treated separators with DIC. The results of the experiments performed in the stored condition and cycled condition are presented in Fig. 2 and Fig. 3, respectively. All images covered a separator area of $288 \mu \mathrm{m} \times 278 \mu \mathrm{m}$ with a resolution of $0.615 \mu \mathrm{m}$. The subset used in DIC processing was $24.6 \mu \mathrm{m} \times 24.6 \mu \mathrm{m}$. Fig. 2a and Fig. 3a show the optical images of the two un-heated (as-received) separators. Fig. 2b-2g and Fig. 3b-3g show the optical images overlapped with the corresponding local strain field maps in both TD (Fig. 2b-2d and Fig. 3b-3d) and MD (Fig. 2e-2g and Fig. 3e-3g) at different conditions. The local strain maps show clearly that the strain was not uniform in the separators, but rather unevenly distributed in a wave-like manner perpendicular to their nominal strain direction, that is, the strain concentration bands of $\varepsilon_{\mathrm{xx}}$ was roughly perpendicular to the TD while $\varepsilon_{y y}$ concentration bands was roughly perpendicular to the MD. Thinner and lightly colored strain bands were found in the stored condition DIC results (Figs. 2b-2g) whereas for the separator in the cycled condition, wider and bright strain concentration strips were presented (Figs. 3b-3g).

The obvious differences of strain distribution in both TD and MD between samples in these two conditions indicate that separator experiences a significant deformation ( $>1 \%$ strain) at elevated temperatures, and the deformation partially recovers once the separator is cooled down (very low strain levels can be found in Fig. 2b-2g). Moreover, for the sample in the cycled condition as shown in Fig. 3, the negative strain concentration strips (compression strain) and the positive ones (elongation strain) were alternately distributed across the surfaces at $50^{\circ} \mathrm{C}$. With an increase in temperature applied, for the transverse strains $\left(\varepsilon_{\mathrm{xx}}\right)$ maps the positive strain bands started to widen at $66^{\circ} \mathrm{C}$, and dominated the strain field map at $90^{\circ} \mathrm{C}$ (Fig. 3b-3d) whereas for the vertical strains $\left(\varepsilon_{\mathrm{yy}}\right)$ the negative strain concentration strips/spots appeared to begin to connect at high temperatures $\left(66^{\circ} \mathrm{C}\right.$ and $90^{\circ} \mathrm{C}$ ), and the averaged negative strain grows significantly from $-1.5 \%$ at $50^{\circ} \mathrm{C}$ to $-6 \%$ at $90^{\circ} \mathrm{C}$, yet no obvious widening of strain strips was found. The above DIC results suggest that for the sample in the cycled condition, strains can be induced by the thermal stress, and as the result of the increase of temperature, separators appear to be elongated in the TD and compressed/shrunk in the MD. It seems that the increase of the compressive strains is partially due to the impact of the adjacent positive (elongation) strains, which is rather obvious in the MD. For the sample in the stored condition, the thermal induced
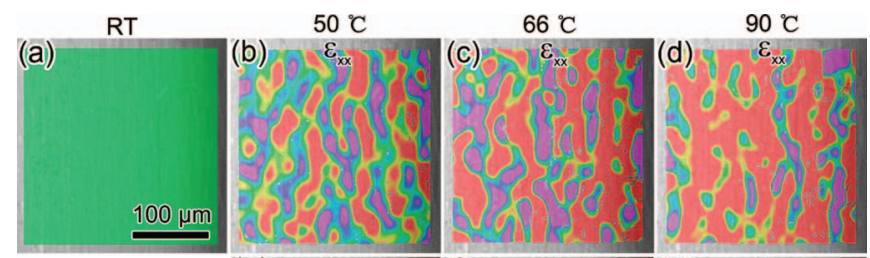

(Cycled condition)
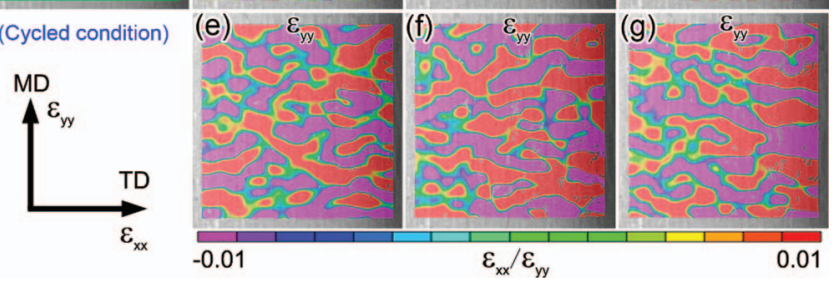

Figure 3. (a) Optical micrograph of separator surface before heating (asreceived). DIC strain maps in the (b-d) transvers direction and in the (e-g) machine direction of the rectangle area in (a) at different temperatures: (b) and (e) $50^{\circ} \mathrm{C}$; (c) and (f) $66^{\circ} \mathrm{C}$; (d) and (g) $90^{\circ} \mathrm{C}$. Arrows under (a) indicate the orientation of the positive color-coded horizontal strain $\varepsilon_{\mathrm{xx}} / \varepsilon_{\mathrm{yy}}$. 


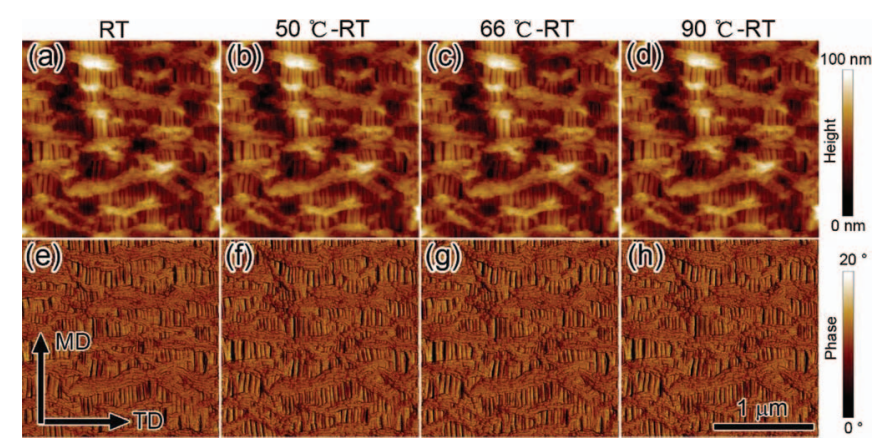

Figure 4. AFM images of separator tested in the stored condition. (a) is the pristine (before heating) height image, (b)-(d) are height images captured at RT after (b) $50^{\circ} \mathrm{C}$, (c) $66^{\circ} \mathrm{C}$, and (d) $90^{\circ} \mathrm{C}$ heat-treatment. (e)-(h) are the phase images corresponding to (a)-(d).

strains can be facilely mitigated as the sample is cooled down to RT. Here it should be stressed that there is no external stress/strain applied during heating/cooling.

Morphology evolution of the separators at elevated temperatures. - Fig. 4 shows the AFM images of separator tested in the stored condition (Fig. $4 \mathrm{a}-4 \mathrm{~d}$ are height images, Fig. $4 \mathrm{e}-4 \mathrm{~h}$ are the corresponding phase images). All the images were obtained from the same area during the in situ AFM-thermal test by using zoom and offset functions in the AFM control software. As shown in AFM images, separator has a slit-like pore structure with lamellae arranged in rows with their long axes parallel to the transverse direction (TD) and nano-sized fibrils bridging the lamellae in the machine direction (MD). The morphology differences between surfaces treated by different temperatures are hardly to distinguish just with our naked eyes. Therefore, we employed the PSD to quantitatively examine the surface structures. As shown in Fig. 5, there is a good overlapping between the PSD measurements in both TD and MD of surface under different temperature heat-treatments except that the PSD for separator surface after $90^{\circ} \mathrm{C}$ treatment shows a slight discrepancy at higher frequencies $\left(>\sim 20 \mu \mathrm{m}^{-1}\right.$ in the TD, $>\sim 80 \mu \mathrm{m}^{-1}$ in the $\mathrm{MD})$. One possible reason for the discrepancy may be structures with a spatial wavelength above $50 \mathrm{~nm}$ were reduced after heat-treatment, which causes the descending of the energy (PSD amplitude) of these structures. Combined with our DIC results in the stored condition, the heat-treatment did not significantly change either the morphology or the surface properties indicated by phase images.

Fig. 6 shows the AFM images of separator surface in the cycled condition. Each image was scanned at the temperature denoted above the height images. From both the height images (Fig. 6a-6d) and the phase images (Fig. 6e-6h), there are some notable changes in the surface at $90^{\circ} \mathrm{C}$ as indicated by green circles: the pores appear to be closed in Fig. 6d; the darker areas in the phase image (Fig. 6h) are found, which are equivalent to a higher delay of the tip and thus to higher local adhesive forces. To further understanding the morphology evo-

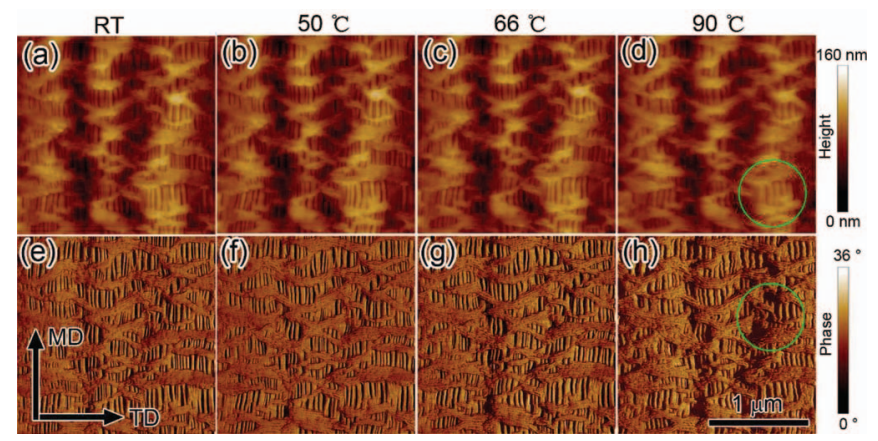

Figure 6. AFM images of separator tested in the cycled condition. (a) Pristine separator (before heating) height image, (b)-(d) are height images captured at (b) $50^{\circ} \mathrm{C}$, (c) $66^{\circ} \mathrm{C}$, and (d) $90^{\circ} \mathrm{C}$. (e)-(h) Phase images corresponding to (a)-(d).
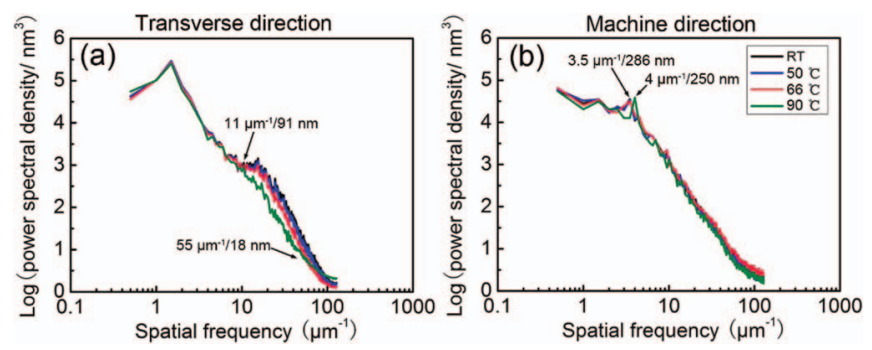

Figure 7. Power spectral density curves in (a) the TD and (b) the MD of separator tested in the cycled condition.

lution, their PSDs as a function of spatial frequency were calculated and shown in Fig. 7. Although the surface morphology of sample at different temperatures looks very similar, there is a pronounced difference in PSD curves in the TD, as illustrated in Fig. 7a. PSD measurements in the TD for surface at $\mathrm{RT}, 50^{\circ} \mathrm{C}$, and $66^{\circ} \mathrm{C}$ overlap conformably whereas the PSD for the surface at $90^{\circ} \mathrm{C}$ is close together with the other three curves at spatial frequencies lower than $11 \mu \mathrm{m}^{-1}$ (wavelength $\sim 91 \mathrm{~nm}$ ), and then it starts to be farther apart from others at higher frequencies, and finally crossed over at the frequency point of $55 \mu \mathrm{m}^{-1}$ (wavelength $\sim 18 \mathrm{~nm}$ ), leaving three different bandwidth regions: $0.5 \sim 11 \mu \mathrm{m}^{-1}, 11 \sim 55 \mu \mathrm{m}^{-1}$, and $55 \sim 128 \mu \mathrm{m}^{-1}$. Essential difference disclosed in the PSD curves indicates that high temperature (up to $90^{\circ} \mathrm{C}$ ) does not remarkably alter surface structures at the range $0.5 \sim 11 \mu \mathrm{m}^{-1}$ while does suppress the structures at the frequency range of $11 \sim 55 \mu \mathrm{m}^{-1}$, and increase the fraction of high frequency of $55 \sim 128 \mu \mathrm{m}^{-1}$ nanostructures in the whole surface. The suppressing of the structures at the range $11 \sim 55 \mu \mathrm{m}^{-1}(18 \mathrm{~nm}-91 \mathrm{~nm})$ is evident in the cross-section analysis from Fig. 8b, which shows that a profile before (blue color) and after (red color) heating still maintains the structure with a wavelength of $36 \mathrm{~nm}$ (formed by two nanofibrils), however, a decreasing of the amplitude of the profile from $10 \mathrm{~nm}$ to
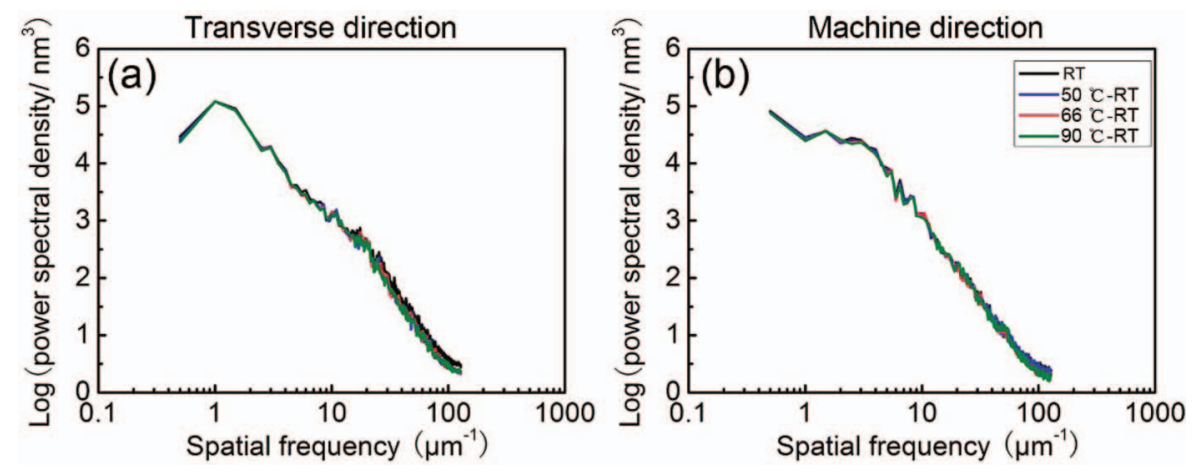

Figure 5. Power spectral density curves in (a) the $\mathrm{TD}$ and (b) the MD of separator tested in the stored condition. 

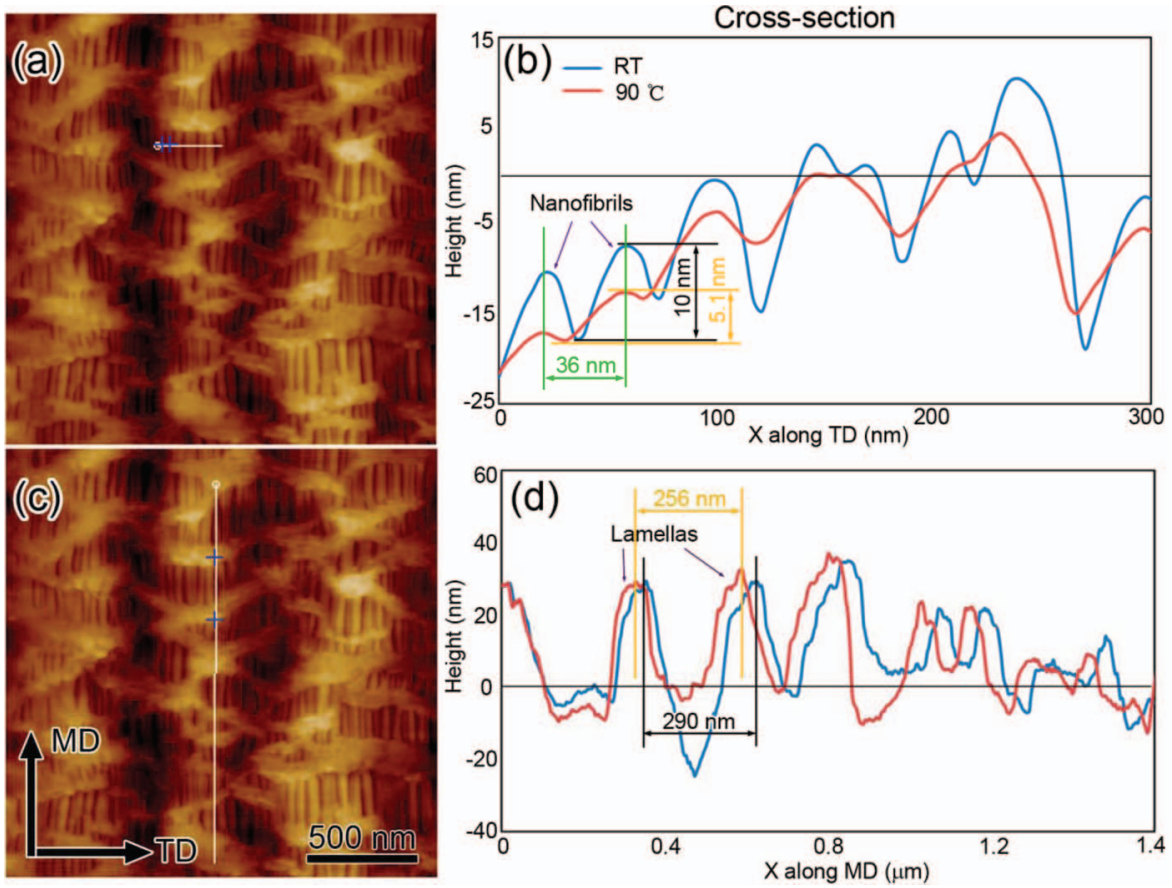

Figure 8. Cross-sections of separator in the cycled condition (a) and (c) are AFM height images of separator at RT, on which lines were drawn to show the positions for cross-section analysis. (b) and (d) are the cross-sections corresponding to the positions shown in (a) and (c), respectively. The values of spatial wavelength and amplitude were denoted on the curves.
$5.1 \mathrm{~nm}$ (the decreasing of pore depth) was remarkably shown. This is in accordance with the known descending energy (PSD amplitude) of PSD curve for surface at $90^{\circ} \mathrm{C}$ at the frequency range of $11 \sim 55$ $\mu \mathrm{m}^{-1}$. This finding can be also taken as further proof that the formation mechanism of pore closure at $90^{\circ} \mathrm{C}$ is by means of dilation of the nanofibrils that surrounding the pore. This dilation of the nanofibrils much below PP's melting temperature is likely due to surface melting effect in nanostructures and should be size dependent-the surface melting temperature may decrease with the diameter of nanofibrils. ${ }^{30}$ Moreover, correlating to the DIC results in the stored condition, the dilated fibrils can be recovered after the removal of heat from the surface.

Besides the changes in the TD, the variation in the MD of surface morphology with temperature can be examined through the MD PSD curves. As shown in Fig. 7b, the PSDs are close for surfaces at different temperatures except that the small peak on the PSD at a spatial frequency of $4 \mu \mathrm{m}^{-1}$ is shifted toward the right (high frequency end) comparing with other curves. The shifting of peak suggests the formation of a periodicity structure with a wavelength of $250 \mathrm{~nm}$ in the surface at $90^{\circ} \mathrm{C}$ that evoluted from the periodicity structure with a wavelength of $286 \mathrm{~nm}\left(3.5 \mu \mathrm{m}^{-1}\right)$. To intuitively understand the formation mechanism, we made a cross-section analysis in the MD. As shown in Fig. 8d, lamellae form a prominent periodic structure having a wavelength equals to the distance between the two adjacent lamellae ( $290 \mathrm{~nm}$ indicated on the profile at RT). When the surface was heated to $90^{\circ} \mathrm{C}$, the wavelength decrease to $256 \mathrm{~nm}$, which demonstrated that the peak shift or periodicity structure evolution in the MD depends on a shrinking mechanism. This is the result of relieving internal stresses present in the separator film after stretching in the MD and quenching the membranes during fabrication. And thus we speculate that the shrinking status should be kept after the surface is cooled down. However, the results of separator tested in the stored condition show most of the strains in both TD and MD on separator surface when cooled down to RT are recovered to zero, that is, almost no shrinkage occurs. The seemingly contradictory dependence on temperature can be explained by a schematic model derived from the DIC and PSD results.

Fig. 9a and 9b schematically illustrate the mechanical behaviors occurred in the separator. The thermal-induced deformation of glued samples (Fig. 9a) can be recovered after surface cooled down whereas (a) Glued at two ends

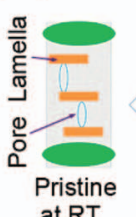
at RT

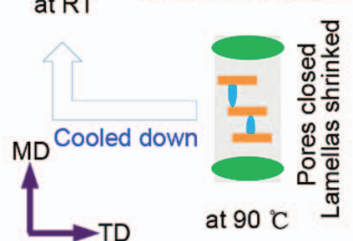

(b) Free-standing

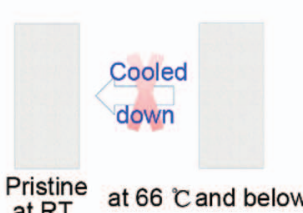

Pristine
at RT

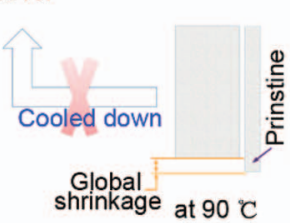

(C) DIC results: strains along the MD

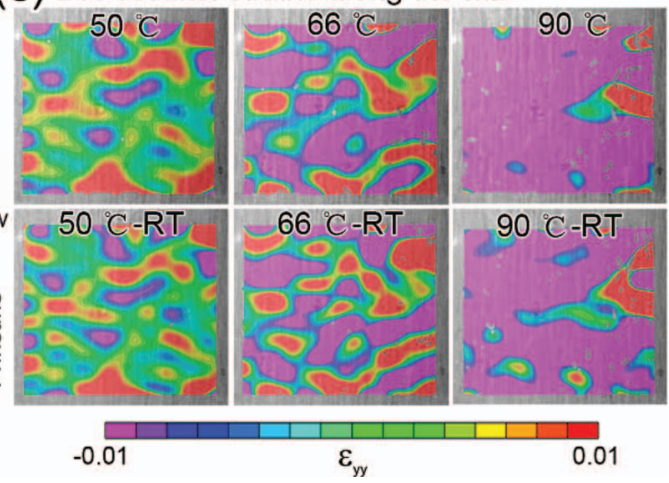

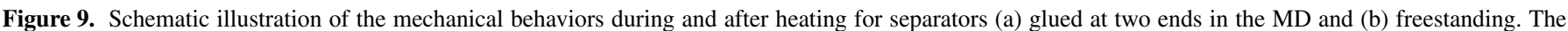

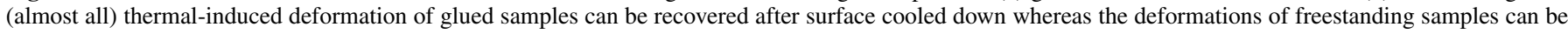

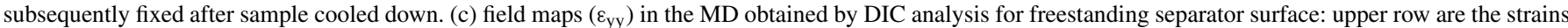

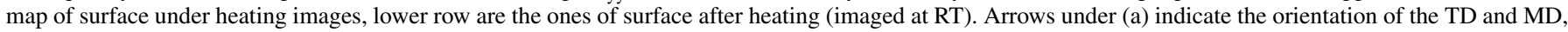
and the positive color-coded horizontal strain $\varepsilon_{\mathrm{yy}}$ is parallel to the MD. 
the deformations of freestanding sample (Fig. 9b) can be subsequently fixed after sample cooled down. The latter was proved by another testin-situ optical imaging and DIC analysis on the freestanding separator. The pristine surface of the sample was first imaged at RT, then the surface was heated up to $50^{\circ} \mathrm{C}$ and captured by optical microscope after 1 hour holding stage, and then cooled down to RT, and surface was imaged at RT again, and as so on for $66^{\circ} \mathrm{C}$ and $90^{\circ} \mathrm{C}$. As shown in Fig. $9 \mathrm{c}$, the field maps were constructed by comparing the optical image (OI) of the pristine surface with the OI of same surface area during heating (upper row in Fig. 9c) and the OI at RT after heating (lower row in Fig. 9c), respectively. The strains (deformation) differences between upper and lower row varies in a small range, base on which we can draw the above conclusion that the deformations of freestanding sample (Fig. 9b) can be subsequently fixed after sample cooled down. Therefore, we can view the freestanding sample as the control sample, and thus the glue as the unique difference between Fig. 9a and $9 \mathrm{~b}$ would be the substantial reason for the recovery of thermal induced strains. This can be readily appreciated: the glue imposes stress on the separator when separator shrinks at $90^{\circ} \mathrm{C}$, and after the separator is cooled down, stress applied by the glue helps retrieve the surface deformation. This "glued" configuration is quite close to real working condition where the separator is under compress and tensile stress, and thus the results shown Fig. 4 and 6 are applicable to probe the separator's mechanical behavior at high temperature in a real battery.

\section{Conclusions}

A coherent picture of the separator's roles in the capacity fade of lithium-ion batteries has been mapped out by coupled temperaturecontrolled AFM imaging, power spectral density (PSD), and digital image correlation (DIC) techniques. Both PSD and DIC analysis results showed that separator when cycled at $90^{\circ} \mathrm{C}$ can significantly close its pores in the TD and shrink in the MD, which will thus increase the cell internal impedance. Note that this happens even below the shutdown temperature $\left(\sim 120^{\circ} \mathrm{C}\right)$ and PP's melting temperature $\left(165^{\circ} \mathrm{C}\right)$. The pore closing proceeds by means of dilation of the nanofibrils surrounding the pores in the transverse direction and shrinkage in the machine direction. The morphology change of the nanofibrils occurred at a temperature that is much lower than PP's melting temperature is likely due to surface melting effect in nanostructures and should be size dependent. If pore closing occurs at high temperature region, it will thus increase the battery internal impedance at temperatures much lower than the designed shutdown temperature, effectively preventing thermal runaway. However, if the surface melting temperature decreases with the diameter of nanofibrils, ${ }^{30}$ some pore closing might happen even at operating temperatures, it will lead to power fade and capacity drop, thus is undesired for battery performance. Therefore, the thermo- mechanical property of the separator is very critical for battery design.

\section{Acknowledgment}

The authors acknowledge the financial support from the Heilongjiang Postdoctoral Foundation of China (LRB07-140). JC acknowledges the financial support from China Scholarship Council. The authors thank Dr. Xiaosong Huang of General Motors for providing separator samples.

\section{References}

1. J. B. Goodenough and Y. Kim, Chem. Mater, 22, 587 (2010).

2. J. Liu, Adv. Funct. Mater., 23, 924 (2013).

3. T. M. Bandhauer, S. Garimella, and T. F. Fuller, J. Electrochem. Soc., 158, R1 (2011).

4. G. L. Henriksen, K. Amine, J. Liu, P. A. Nelson, and P. A. Materials Cost Evaluation Report for High-Power Li-Ion HEV Batteries, in, The University of Chicago, Argonne (2002). http://www.ipd.anl.gov/anlpubs/2003/01/45346.pdf.

5. P. Ramadass, B. Haran, R. White, and B. N. Popov, J. Power Sources, 112, 606 (2002).

6. K. Amine, J. Liu, and I. Belharouak, Electrochem. Commun., 7, 669 (2005).

7. P. Liu, J. Wang, J. Hicks-Garner, E. Sherman, S. Soukiazian, M. Verbrugge, H. Tataria, J. Musser, and P. Finamore, J. Electrochem. Soc., 157, A499 (2010).

8. N. Yabuuchi and T. Ohzuku, J. Power Sources, 146, 636 (2005).

9. S. Ma and H. Noguchi, J. Power Sources, 161, 1297 (2006).

10. L. Bodenes, R. Naturel, H. Martinez, R. Dedryvère, M. Menetrier, L. Croguennec, J.-P. Pérès, C. Tessier, and F. Fischer, J. Power Sources, 236, 265 (2013).

11. E. V. Thomas, H. L. Case, D. H. Doughty, R. G. Jungst, G. Nagasubramanian, and E. P. Roth, J. Power Sources, 124, 254 (2003).

12. G. M. Ehrlich, in Handbook of Batteries, 3rd ed., D. Linden and T. B. Reddy Editors, p. 35.71, McGraw-Hill, New York (2002).

13. E. Markevich, E. Pollak, G. Salitra, and D. Aurbach, J. Power Sources, 174, 1263 (2007).

14. A. M. Andersson and K. Edström, J. Electrochem. Soc., 148, A1100 (2001)

15. X. Huang, J. Solid State Electrochem., 15, 649 (2011).

16. S. S. Zhang, J. Power Sources, 164, 351 (2007)

17. X. Huang and J. Hitt, J. Membr. Sci., 425-426, 163 (2013).

18. J.-J. Woo, S. H. Nam, S.-J. Seo, S.-H. Yun, W. B. Kim, T. Xu, and S.-H. Moon, Electrochem. Commun., 35, 68 (2013).

19. C. J. Orendorff, T. N. Lambert, C. A. Chavez, M. Bencomo, and K. R. Fenton, $A d v$. Energy Mater, 3, 314 (2013).

20. H. Xiang, J. Chen, Z. Li, and H. Wang, J. Power Sources, 196, 8651 (2011).

21. W.-K. Shin and D.-W. Kim, J. Power Sources, 226, 54 (2013).

22. D. Fu, B. Luan, S. Argue, M. N. Bureau, and I. J. Davidson, J. Power Sources, 206, 325 (2013).

23. L. Norin, R. Kostecki, and F. McLarnon, Electrochem. Solid-State Lett., 5, A67 (2002).

24. R. Kostecki, L. Norin, X. Song, and F. McLarnon, J. Electrochem. Soc., 151, A522 (2004).

25. J. Chen, T. Sun, and J. Wang, in 5th International Symposium on Advanced Optical Manufacturing and Testing Technologies: Optical Test and Measurement Technology and Equipment, p. 76562D, Dalian, China (2010).

26. Y. Qi and S. J. Harris, J. Electrochem. Soc., 157, A741 (2010).

27. X. Li, W. Xu, M. A. Sutton, and M. Mello, IEEE T. Nanotechnol., 6, 4 (2007).

28. J. Chen, J. Liu, Y. Qi, T. Sun, and X. Li, J. Electrochem. Soc., 160, A1502 (2013).

29. M. A. Sutton, C. Mingqi, W. H. Peters, Y. J. Chao, and S. R. McNeill, Image Vis. Comput., 4, 143 (1986).

30. Y. Qi, T. Çağin, W. L. Johnson, and W. A. Goddard, J. Chem. Phys., 115, 385 (2001). 